\title{
TECNOLOGIA ASSISTIVA (TA) E ALUNOS COM DEFICIÊNCIA VISUAL: UM RECORTE SOBRE REPRESENTAÇÕES NA DISPUTA ENTRE BRAILLE E DOSVOX
}

\author{
Cristiane Correia Taveira, IHA/SME-Rio, PUC-Rio - \\ cristianecorreiataveira@gmail.com \\ Luiz Alexandre da Silva Rosado, PUC-Rio, Bolsista da CAPES - \\ alexandre.rosado@globo.com
}

\begin{abstract}
RESUMO
A partir de um recorte contendo diálogos via e-mails entre uma aluna com deficiência visual da rede municipal do Rio de Janeiro, professores da $2^{\text {a }}$ CRE e elementos de equipe de acompanhamento, analisam-se modos de representar e lidar com a inserção de TICs, especialmente aquelas que visam maior acessibilidade aos formatos digitais, cada vez mais presentes no âmbito das Tecnologias Assistivas. Realizou-se também o cotejo entre a tecnologia impressa do Braille, utilizada como referencial de prática de leitura / escrita pelos envolvidos, e o suporte oferecido pelo programa Dosvox, objetos em disputa nos discursos. As representações em jogo incluem como elementos concepções do que seria a ajuda mais adequada para esta aluna - mesmo que sua fala seja negada em certo momento - passando pela dicotomia sou contra / sou a favor, embora não diretamente admitida pelos envolvidos, assim como novas possibilidades de acesso a elementos culturais e facilidades nos quesitos conforto e ergonomia.
\end{abstract}

Palavras-chave: deficiência visual; tecnologia assistiva; educação inclusiva.

\section{ASSISTIVE TECHNOLOGY (AT) AND STUDENTS WITH VISUAL IMPAIRMENTS: A CLIPPING ON THE DISPUTE BETWEEN BRAILLE AND DOSVOX REPRESENTATIONS}

\begin{abstract}
From a clipping containing dialogues via e-mail from a student with visual impairment in a school of the municipal of Rio de Janeiro, teachers of the $2^{\text {nd }}$ CRE and elements of the monitoring team, we examine ways to represent and deal with the integration of ICTs especially those aimed at greater accessibility to digital formats, increasingly present in the context of Assistive Technologies. Was also carried out the comparison between the technology of printed Braille, as a benchmark of practice reading and writing by those involved, and the support offered by the program Dosvox, objects in dispute in discourse. The representations include elements such as concepts of what would be the most appropriate help for this student - even though her speech is denied at one time - through the dichotomy I'm against / I support, although not directly admitted by those involved, as well as new possibilities access to information and cultural facilities in the categories ergonomic and comfort.
\end{abstract}

Keywords: visual impairment; assistive technology; inclusive education.

\section{Introdução: deficiência e barreiras comunicacionais}

No caso da inclusão de alunos com deficiência, observa-se a necessidade de grupos de professores redesenharem novos perfis em relação ao conceito de inclusão, onde parecem caber negociações e renegociações do que seja a diferença a ser 
incorporada em sala de aula e, também, de quais sejam os modos de agir, o saber prático de que lançam mão os professores e os alunos diante do trabalho com diferentes necessidades.

Ainda persiste o ideal de aluno que copia do quadro, escreve a lápis e caneta no caderno, possui desenvotura oral (fala) e autonomia. Questiona-se, afinal, o que se espera dele em termos de desempenho escolar e o que se entende por autonomia. Autonomia essa contendo implicitamente a não-necessidade da ajuda do outro, sendo aquela que se procura e se espera encontrar nos bancos escolares.

O quadro de estigmatização do aluno com deficiência costuma decorrer das expectativas, valores e crenças do professor em relação à aprendizagem da criança, jovem ou adulto com deficiência, o que pode ter conseqüências nas percepções sobre o processo de inclusão.

Barreiras de comunicação e de acesso à informação geram conseqüências no processo de inserção, uma vez que o avanço deste aluno em seus estudos, ou a descrença e a inviabilidade deste avanço nesta turma e escola, podem ficar subordinados aos resultados dos contatos com o ambiente escolar e do que se imagina serem facilitações e ajudas oferecidas às pessoas com deficiência.

\section{Metodologia e referencial teórico de estudo}

Essa pesquisa tem como objetivo entender o sentido atribuído pelos professores à inclusão dos alunos com deficiência que necessitam de Tecnologia Assistiva (TA) em turmas comuns. Procura-se identificar em suas falas indícios do senso comum que indicam os modos de representação a respeito de tecnologias, especialmente aquelas de configuração digital, recentemente inseridas na sociedade e representadas pelo computador e suas variantes (tocadores portáteis de música, máquinas de fotografar, jogos eletrônicos e computadores de uso pessoal).

Os sujeitos são os professores do Ensino Público Municipal do Rio de Janeiro, que atuam com alunos com deficiência inseridos em classes comuns de escolas da $2^{\mathrm{a}}$ Coordenadoria de Educação ( $2^{\mathrm{a}} \mathrm{CRE}$ ). O objeto de estudo são as percepções destes professores frente ao processo de inclusão de práticas educativas necessárias e da Tecnologia Assistiva delimitada e ofertada aos alunos. Faz-se o recorte de uma situação a respeito de uma aluna cega que possui paralisia cerebral. Esta paralisia acarretou alguma dificuldade motora no lado direito, não a impedindo de escrever, mas dificultando (ver Anexo I para detalhamento do contexto escolar dessa aluna).

Como referencial de análise, a teoria das representações sociais possibilita compreender como o tripé grupos-atos-idéias constitui e transforma a sociedade. Moscovici (1978, 2003) preocupou-se com o estudo de como e por que as pessoas partilham o conhecimento, de que modo elas transformam as idéias em práticas e, dessa maneira, constroem a realidade comum. Em síntese, Moscovici interessou-se no "poder das idéias” de senso comum (Oliveira, 2004).

Entende-se, em representações sociais, que nos julgamentos e posições manifestados na vivência diária o indivíduo acredita que algo é verdade ou mentira em relação às expectativas do outro e dos grupos aos quais pertence, em sua atuação frente ao mundo. Esta dinâmica de um saber prático pressupõe idéias, noções, significações ligadas a percepções e sentimentos.

Não é suficiente narrar em detalhes o que se passa na escola, é necessária uma aproximação das significações e intenções do grupo de professores e de alunos em ação, para que se atinja a compreensão do processo de construção das representações sociais, 
de modo que seja possível compreender a ordem das interações, sendo estas afetivas, materiais e simbólicas.

A representação social é uma ação simbólica do sujeito/grupo na relação com o mundo, uma espécie de filtragem por meio dos valores e informações no processo de decodificação e codificação do mundo que o rodeia e que incide diretamente na vivência prática, no saber agir (Jodelet, 2001, 2005).

No caso da inclusão de alunos com deficiência, observa-se a necessidade de grupos de professores desenharem e redesenharem novos perfis em relação ao conceito de inclusão, onde parecem caber negociações e renegociações do que seja a diferença a ser incorporada na sala de aula e, também, de quais sejam os modos de agir, o saber prático de que lançam mão os professores diante do trabalho com diferentes necessidades.

Os aspectos de apresentar padrão de resposta ideal, de atender a normas, instauram posicionamentos e valores no grupo de professores e de alunos, instituem práticas de acordo com julgamentos, com representações sociais, o que não se deixa ver, num primeiro plano, que modelos normativos (modelos de cultura) estão em jogo.

Observou-se, na inclusão do jovem com deficiência visual, que os processos excludentes podem ficar ocultos ou em segundo plano de discussão, visto que não se limitam aos aspectos econômicos e sociais. A partir da não-observância das características de faixa etária (adolescente) e da não-atenção a opinião do aluno com deficiência (jovem cega) em relação aos diversos usos de tecnologia, há processos simbólicos que promovem a manutenção de práticas massificadoras com a racionalização e legitimação dessas pelos profissionais de educação. Daí a importância de se recorrer a uma abordagem psicossocial para que se possa entender de que modo as representações sociais resistem aos apelos da inserção de Tecnologias Assistivas que privilegiem acessibilidade.

Grupos de professores podem se manifestar na ação comunicativa entre seus pares, pelas relações de instituições, de posicionamentos e de poder admitindo e aprovando a manutenção de modo único e não dialogado de prática educativa, o que pode resultar em resistência ativa por parte do alunado.

Os desafios apresentados pelas diferenças comportamentais, multiplicidade de características sociais, emocionais, físicas de alunos tornam o ambiente da escolarização imprevisível na visão do professor. São aspectos que parecem deflagrar a defesa da ordem e do controle e provocar a busca pela homogeneização de comportamentos. Estes aspectos presentes em valores, atitudes e práticas, nas representações sociais, incidem sobre o modo de lidar com a utilização das tecnologias pelos estudantes, incluindo a Tecnologia Assistiva para o aluno com deficiência.

\section{O conceito de Tecnologia Assistiva}

A autora Rita Bersch (2008) nos aponta o intenso uso de tecnologia em nosso dia-a-dia para tornar nossa vida mais simples e fácil. Utilizamos canetas, tesouras, computadores, controle remoto, celulares. Estes elementos já estão imersos e assimilados em nosso dia a dia e fazem parte de nossa formação cognitiva, afetiva e social.

No entanto, em relação à tecnologia, a autora apresenta a partir de Radabaugh (1993) que estes recursos, derivados de avanços tecnológicos, tornam as coisas mais fáceis para as pessoas sem deficiência e acrescenta que para pessoas com deficiência a tecnologia torna as coisas possíveis. 
A Tecnologia Assistiva deve ser então entendida como equipamentos, serviços, estratégias e práticas que precisam ser planejadas e aplicadas na promoção e ampliação de uma habilidade funcional deficitária, distante do que é interpretado como essencial pelo grupo ao qual o indivíduo se insere.

Neste sentido há que se ter uma discussão sobre valores e modelos de cultura em jogo no ambiente escolar quanto ao que seja a normalidade, para que não se pretenda solicitar ações dispensáveis como, por exemplo, elencar a Tecnologia Assistiva para suprir ou alavancar certa habilidade, desconsiderando o desejo do aluno ou outros meios para que se atinjam os mesmos resultados.

Em atividade de pintura ou recorte e colagem, um aluno pode ser treinado a usar um equipamento numa ação que beire a tortura de movimentos repetitivos ao invés de investir na colaboração entre os pares (um aluno desenha, outro pinta, outro recorta, todos colaboram com a criação). Em contrapartida, a não apresentação de equipamentos para experimentação pode se configurar na privação de oportunidades de conhecer e escolher o que se quer ou não fazer e de que modo. É preciso enxergar a TA a partir das necessidades peculiares a cada sujeito e grupo.

A TA traz a possibilidade de realização de uma função esperada como, por exemplo, a capacidade de expressão oral e escrita, assim como a alternativa e ampliação da condição de comunicação, que se encontra impedida por inúmeros fatores, tais como: circunstância de deficiência (situações permanentes ou transitórias); envelhecimento; circunstâncias transitórias acarretadas por quadros clínicos num dado período de vida (causada por acidentes, cirurgias); e em situações graves acarretadas por síndromes e doenças (lesões por acidente vascular cerebral dentre outras) (Bersch, 2008; Pelosi, 2000).

Bersch (2008, p. 1) sinaliza que

o objetivo maior da TA é proporcionar à pessoa com deficiência maior independência, qualidade de vida e inclusão social, através da ampliação de sua comunicação, mobilidade, controle de seu ambiente, habilidades de seu aprendizado e trabalho.

Sobre o conceito brasileiro de TA, a Coordenadoria Nacional para Integração da Pessoa Portadora de Deficiência (CORDE) é o órgão de assessoria da Secretaria Especial dos Direitos Humanos da Presidência da República (SEDH/BR). Em 16 de novembro de 2006, a SEDH, por meio da portaria $n^{\circ}$ 142, instituiu o Comitê de Ajudas Técnicas que reúne um grupo de especialistas brasileiros e representantes de órgãos governamentais (Bersch, 2008, p. 2-3).

A princípio, o CAT se deteve numa profunda revisão no referencial teórico internacional, pesquisando os termos Tecnologia Assistiva, Tecnologia de Apoio, Ajudas Técnicas, Ayudas Tecnicas, Assistive Technology e Adaptive Technology. Após esta revisão, o conceito apresentado pela Comissão, pelo CAT, foi o seguinte:

Tecnologia Assistiva é uma área do conhecimento, de característica interdisciplinar, que engloba produtos, recursos, metodologias, estratégias, práticas e serviços que objetivam promover a funcionalidade, relacionada à atividade e participação, de pessoas com deficiência, incapacidades ou mobilidade reduzida, visando sua autonomia, independência, qualidade de vida e inclusão social (CORDE - Comitê de Ajudas Técnicas - ATA ${ }^{1}$ VII, 2007).

Nesta descrição percebemos a abrangência da área de conhecimento de TA, que extrapola a concepção de lista de produtos (objetos, equipamentos e/ou dispositivos), e 
agrega atribuições que correspondem a estratégias, a serviços e a práticas que favoreçam o desenvolvimento de habilidades de pessoas com deficiência.

\section{Braille e Dosvox em disputa: descrição sintética de uma situação de conflito}

A partir de uma conversação via e-mail foram detectadas algumas expressões que evidenciam modos de se lidar com a inserção de tecnologias derivadas da computação digital no meio escolar, tratadas e sintetizadas a seguir. Neste caso específico, o computador (PC / Notebook) tem como finalidade a ampliação da capacidade de comunicação da aluna que apresenta deficiência visual, permitindo que através de um teclado e de sintetizador de voz ela possa manipular dados digitais, sejam em forma de texto ou em áudio sintetizado/gravado.

Para iniciar, vemos que aluna faz um desabafo sobre a maneira como entende ser a mais fácil para acesso à informação, sendo que o software utilizado por ela é o Dosvox $^{2}$. Porém a posição da aluna gerou uma discussão entre os professores que a acompanham. A seguir a opinião da aluna com deficiência física e cegueira, de $6^{\circ}$ ano, transcrição de e-mail enviado em 2 de fev. de $2008^{3}$ :

\footnotetext{
Já percebeu o que a professora tá querendo?

Ela tá medindo forças comigo.

Ela disse assim em um dos e-mails: "Experimenta ficar só com o dosvox."

Vou responder pra vc, só pra não perder a paciência com ela: Bem,... Minha amiga não usa o braille.

Ela leva o notebook pra escola, faz os dvs de casa no computador e manda para o professor por e-mail.

Com isso eu digo pra vc: Ficaria, sim, se fosse possível, somente com o dosvox Além do braille cansar muito minha mão esquerda, farei os deveres mais rápido.
}

A aluna participou de Jornada de Educação Inclusiva, no Município do Rio de Janeiro, promovida pelo Instituto Municipal Helena Antipoff (SME/Rio), e relatou impressões de que a introdução do Dosvox facilitava o ir e vir nas questões de provas, agilizava a realização das mesmas e, principalmente, pela dificuldade motora, cansava menos as mãos (uso de teclado no computador) em relação à utilização da máquina Perkins (peso das teclas).

Analisaremos então a discussão ocorrida em conseqüência deste e-mail, sobre a introdução do uso do Dosvox, dos aparelhos de captação e reprodução de áudio MP3, como recursos para gravação e acesso de aulas e de informações, num processo de oferecimento de tecnologias, que facilitaram a vida escolar dos alunos inseridos em turma comum de $6^{\circ}$ ano, e que, ao mesmo tempo, não foram apropriados por alguns jovens, por motivos de responsabilidade dos mesmos, principalmente, na realização de tarefas de pesquisa e de leitura (ver maiores detalhes destas apropriações no Anexo I). Tal processo provocava insatisfação de alguns professores pelo não-cumprimento de deveres escolares e acarretavam a não-credibilidade e não-autorização de investimentos nessas tecnologias.

Em resposta ao e-mail da aluna, a professora da sala de recursos enfocou a equivalência de funções e a necessidade da diversidade dos meios. $\mathrm{O}$ ato de ir e voltar em um texto é enfatizado como necessário pela professora, sugerindo que as idas e vindas ocorrem de maneira semelhante no Braille e no Dosvox. A professora não vê problema no uso do Braille, não atentando para a reclamação da aluna que não se sente a vontade com a digitação na máquina Perkins, que é cansativa. Não é feito em nenhum momento uma distinção entre a leitura visual (utilizada pelos videntes) e a leitura táctil 
(utilizada pelos deficientes visuais), assim como os seus modos de varredura e busca no texto.

Em resposta, a professora da equipe de acompanhamento da educação especial levanta três critérios para análise do Dosvox e do Braille: a praticidade, o conforto e a rapidez no trato com a informação. Ela enfatiza também que a comparação entre os dois deve ser realizada a partir da experiência prática de uso por parte dos alunos, que muitas vezes desconhecem o Dosvox. O modo de construção da fala interna é posto como critério que distingue o Dosvox (leitura em ritmo contínuo e imposto pelo sintetizador) e o Braille (leitura no ritmo e velocidade controlados pelo leitor).

Na fala da professora itinerante o conforto e a eficácia mais uma vez são citados como critérios, a serem aferidos através da prática dos alunos. O conforto é traduzido através do peso da máquina Perkins e o esforço para digitar nela, em contraste com a leveza de um notebook. A eficácia é medida pela diminuição do peso e da quantidade de papel impresso. Apesar de ser a favor explicitamente da tecnologia digital, ela pondera que o Dosvox e o Braille têm prós e contras que devem ser analisados.

Por fim, observamos mais uma vez a professora da sala de recursos, que inicialmente atenta para a dicotomia estar contra / estar a favor e se posiciona a respeito da informática como “óbvia” em seus benefícios, mas não crê em substituição de recursos. Em seu desenvolvimento argumentativo o Braille mais uma vez é comparado ao papel impresso, mesmo que os tipos de leitura e de escrita sejam distintos. O texto em Braille é posto como tecnologia que não será substituída, pondo em equivalência o texto impresso com tinta e sua permanência mesmo após o surgimento da computação. O papel da tecnologia quanto aos fatores conforto, agilidade e autonomia é negado como variável de influência. A tecnologia é questionada em sua eficácia pedagógica (dois processos que em si são distintos, mesmo que muitas vezes interligados), associando-se a apreensão, significação e interesse em conteúdos escolares com o conforto e agilidade comunicacional requerida pela aluna. Vale destacar que no meio do texto há uma repreensão pelo fato da aluna-usuária se expressar a respeito da utilização do Dosvox, fato este recebido como intrusão em um debate que deveria ocorrer somente entre os professores.

Nesta fase a aluna entra, se defende, explica que os professores oferecem tempo, na escola, para feitura dos deveres. Reclama do peso da máquina Perkins ao ser carregada para os diversos espaços da escola, da sala de recursos e outras atividades. A aluna passa o tempo, quando em casa, no Orkut, $\mathrm{MSN}^{4}$ e não estaria correspondendo às solicitações de estudo. O professor de introdução ao Dosvox, de informática, ressalta que os alunos precisam sentir, desejar o uso dos recursos ora apresentados e faz parte do universo adolescente (e não especificamente da aluna) esta baixa adesão e responsabilidade com trabalhos de casa.

O último posicionamento na discussão, do referido professor (que possui baixa visão), começa por recusar a dicotomia estar contra / estar a favor. Ele afirma que há uma equivalência de importância entre os dois meios de comunicação. Apesar disso, o Dosvox é analisado em suas novas possibilidades que não existem no Braille. Podemos citar: fazer compras, buscar informações culturais, lazer, e ler um jornal on-line. A capacidade de ampliação do contato com a produção cultural e a interação social também são levantados. Ele conclui dizendo que o critério de ampliação de opções e recursos é apresentado pelo professor, assim como a capacidade de escolha é dada ao aluno.

\section{Discutindo os dados:}




\section{oposição entre tecnologias, abertura de possibilidades e representações sobre seus usos}

Percebemos nos discursos uma leve disputa, não extremada e nem muito menos radical, entre o que Umberto Eco (1993) denominaria de posição dos apocalípicos, que vêem a tecnologia como ameaça à integridade do ser humano no mundo, ameaçando sua cultura e valores por uma reprodutibilidade irrefreada de bens, e integrados, que concebem as novas tecnologias a partir de seus benefícios e utilidades práticas, aceitando-as de modo natural, sem maiores resistências e como benéficas a todas as camadas sociais que delas fizerem uso e imersão. Equivalente nomenclatura separaria em dois extremos os tecnofílicos dos tecnofóbicos (Breton, 2000), oposição presente e recorrente quando um novo meio tecnológico é inserido em um ambiente social, gerando mudanças e resistências aos seus novos usos ${ }^{5}$.

É um debate focado no artefato, no objeto técnico, como produtor de alterações e condicionamentos sociais, o que evidentemente não é nosso foco e objetivo neste trabalho. Assumimos aqui que são as pessoas, em seu uso cotidiano dos objetos técnicos, que fazem e refazem seus usos através de uma apropriação dinâmica e criativa, como nos aponta Lemos em sua análise sobre a criatividade dos usos na cibercultura (Lemos, 2007). Também percebemos que o debate gira em torno da adesão e uso do novo objeto técnico, sendo o computador mais versátil, pois, além de objeto de leitura e escrita, é objeto comunicacional quando conectado a uma rede de dados como a internet. É mais versátil, porém ele não determina em si mesmo os usos, mas condiciona a partir do momento que oferece estruturas e formas de interação características de seu formato, nos levando a concordar com a afirmação de Lévy (1999) de que a técnica, antes de determinar usos e culturas, é condicionante e não a causa em si mesma.

Semelhantes transições de meios técnicos e reações de rejeição ou adesão (estar contra / estar a favor), que afetam os modos de se portar e a cultura em si mesma, são descritas por Chartier (2007) quando detecta em textos literários descrições indicando oposição entre as antigas tábuas de cera, utilizadas para anotações efêmeras (contas a pagar, registros de compra e venda, rascunhos de poemas) e o crescente uso do papel como fixador da criação literária a partir do século XVI na Europa, com a difusão da imprensa. Não foram poucas as reações de descrença quando jornais impressos começaram a substituir os manuscritos de notícias, em que se argumentava que uma vez difundidos os textos em jornais, estariam então acessíveis a pessoas ignorantes e incapazes de compreendê-los.

A concepção do computador como objeto causador de decadência de hábitos considerados saudáveis e fonte causadora de perdas culturais também ressurge no imaginário da contemporaneidade, em especial com as novas configurações da autoria em que a facilidade de acesso à informação gera a facilidade para o plágio e a perda de fontes de informação sólidas e confiáveis, o que levaria as novas gerações a um grau de superficialidade cultural ameaçador (Keen, 2009).

Apesar desta distinção opositiva a princípio clara nos discursos, não foi realizado um cotejo preciso a respeito das aproximações e diferenças entre as duas tecnologias em “disputa” nos discursos: o Braille e o Dosvox. Vejamos então um quadro onde se procurou breve análise a partir de alguns critérios surgidos ao longo das discussões e outros criados pelos autores:

Tabela 1 - Confronto entre os usos do Dosvox e do Braille.

\begin{tabular}{|l|l|l|}
\hline Critérios & DOSVOX & BRAILLE \\
\hline $\begin{array}{l}\text { Agilidade e } \\
\text { Conforto }\end{array}$ & $\begin{array}{l}\text { - Permite a digitação rápida no teclado, } \\
\text { assim que a posição das teclas é aprendida }\end{array}$ & $\begin{array}{l}\text { - Permite a digitação rápida, mas com } \\
\text { dificuldade pelo “peso” de digitação }\end{array}$ \\
\hline
\end{tabular}




\begin{tabular}{|c|c|c|}
\hline & pelo aluno. & das teclas. \\
\hline Eficácia & $\begin{array}{l}\text { - Menos consumo de folhas. } \\
\text { - Menor peso (notebook). } \\
\text { - Depende de energia elétrica e presença de } \\
\text { tomadas. }\end{array}$ & $\begin{array}{l}\text { - Elevado número de folhas. } \\
\text { - Maior peso da máquina Perkins. } \\
\text { - Independe de tomadas e baterias. }\end{array}$ \\
\hline Leitura & $\begin{array}{l}\text { - Leitura através de interpretador por voz } \\
\text { sintetizada. } \\
\text { - Capacidade de buscar palavras-chave. } \\
\text { - Permite pausas na leitura. }\end{array}$ & $\begin{array}{l}\text { - Leitura táctil. } \\
\text { - É necessário percorrer cada linha do } \\
\text { texto para encontrar a informação } \\
\text { desejada. } \\
\text { - Permite pausas na leitura. }\end{array}$ \\
\hline $\begin{array}{l}\text { Possibilidades } \\
\text { extras }\end{array}$ & $\begin{array}{l}\text { - Comunicação (e-mail / mensageiros } \\
\text { instantâneos / redes sociais). } \\
\text { - Compras, Cultura e Lazer. }\end{array}$ & - Instrumento de leitura e escrita. \\
\hline Tipo de leitor & $\begin{array}{l}\text { - Fragmentário com múltiplos acessos a } \\
\text { recursos. } \\
\text { - Hipertextual, com acesso a assuntos } \\
\text { correlatos. }\end{array}$ & $\begin{array}{l}\text { - Linear e seqüencial, a princípio. } \\
\text { - Há o potencial para índices e } \\
\text { remissões hipertextuais, porém não } \\
\text { muito eficaz. }\end{array}$ \\
\hline $\begin{array}{l}\text { Interfaces e } \\
\text { sentidos }\end{array}$ & $\begin{array}{l}\text { - Táctil: teclado. } \\
\text { - Auditiva: sintetizador de voz e fala } \\
\text { interior que o acompanha. } \\
\text { - Vocal: gravação da aula e de falas } \\
\text { próprias. } \\
\text { - Visual: facilidade do vidente (aluno / } \\
\text { professor / pais / amigos) em ler os textos } \\
\text { digitados pelo deficiente visual. }\end{array}$ & $\begin{array}{l}\text { - Táctil: relevo dos caracteres. } \\
\text { - Auditiva: maior controle sobre o } \\
\text { ritmo da fala interior. } \\
\text { - Visual: limitada a videntes que } \\
\text { conhecem o Braille. }\end{array}$ \\
\hline Portabilidade & $\begin{array}{l}\text { - Memória com capacidade virtualmente } \\
\text { infinita de textos. }\end{array}$ & $\begin{array}{l}\text { - Limitação do peso dos papéis e } \\
\text { espaço de locação. }\end{array}$ \\
\hline
\end{tabular}

Por este quadro, é possível realizar um esforço inicial na busca das representações sociais de professores envolvidas quando se insere um novo objeto comunicacional em cena, sendo neste caso a tecnologia computacional utilizada no Dosvox.

Observamos que a representação da professora a respeito do Dosvox parte do uso já conhecido do Braille e mesmo da leitura em suporte impresso com tinta (folha de papel impressa), colocando em paralelo modos de ser leitor e de realizar a leitura que não são necessariamente equivalentes e automaticamente comparáveis. Ler e escrever em Braille não é o mesmo que ler e escrever através do computador com sintetizador de voz, exigindo modos de varredura no texto, mobilização de sentidos e operações cognitivas bem distintas.

O viés mais "apocalíptico" pode vir quando se relaciona o uso do Dosvox a um empobrecimento do estudo, da ortografia e da autonomia do aluno, criando-se barreiras comunicacionais travestidas de proteção e defesa pedagógicas. Dessa forma a representação da professora sobre a tecnologia digital reflete uma resistência em observar e alterar sua própria rotina e prática escolar, apesar de negar a postura dicotômica de estar contra / estar a favor.

Esse modo de representar, trazendo um conceito de leitura construído a partir de suportes já conhecidos (livro, folha de papel), acaba por impedir uma análise mais contextualizada das necessidades do aluno com deficiência visual, não se atentando para suas experiências de vida e mesmo procurando-se excluir este aluno dos debates, desqualificando suas reflexões sobre a própria prática. Comunicar-se é utilizar-se de instrumentos que o mundo dispõe (linguagem e objetos) para acessar o pensamento e a expressão do outro. Pergunta-se então: independentemente dos instrumentos mobilizados, esta aluna com deficiência visual está se comunicando bem? É preciso 
então pensar a biografia da aluna e seu contexto, assim como o uso dos canais sensoriais que possui (Laplane \& Batista, 2008, p. 215-216).

O que observamos é que a inserção de um novo objeto técnico complexifica o meio através da relação dialética entre seus elementos (complexa rede de atores em contato e uso de objetos), ressituando o sujeito e trazendo possibilidades de usos e apropriações que muitas vezes não são previstas (seja pelo professor ou pelo próprio aluno), devendo-se observar primeiro seus usos práticos (cotidiano), para depois intervir e, caso possível, melhorar a forma de aprendizagem a partir deles.

O formato digital, ainda em fase de compreensão sobre seus usos e efeitos, pode já estar em vias de modificar o formato impresso em Braille (recursividade), alterando a própria natureza do suporte "tradicional". Como exemplo, temos as superfícies maleáveis em que os relevos em Braille se modificam, tais como a imagem dinâmica que os videntes já se familiarizaram através do monitor do computador, passando para o formato táctil e digitalmente processado os textos presentes na internet. A ergonomia também deve ser levada em consideração, a exemplo do peso dos livros em papel e da máquina Perkins, que geram visível desconforto, conforme a narrativa da aluna.

\section{Considerações finais}

A necessidade de ter a pessoa com deficiência visual como co-partícipe da avaliação sobre o uso do computador, observando-a no lugar onde ocorrem os usos escolares, faz-se necessária para o aprofundamento de políticas de acesso à informação que não dicotomizem ou radicalizem vantagens e desvantagens da tecnologia digital, comparando suportes de leitura e escrita desvinculados de seu uso cotidiano.

As novas formas de construção do conhecimento pelo uso da internet na sociedade contemporânea precisam ser consideradas, especialmente a partir da cultura midiática juvenil (Garbin, 2003; Freitas, 2005) extra-escolar, que está em plena fase de adaptação ao formato digital, especialmente a que se forma em comunidades virtuais e redes sociais suportadas por sites na internet (Recuero, 2009), e sua influência em espaços escolares. Afinal, por que os alunos não se apropriam desse meio para efetivamente aprofundarem os conteúdos escolares? Esta questão está atrelada ao que seja o conhecimento legitimado pela escola (temas e assuntos curriculares) e como o aluno o apreende e significa para si.

No entanto, por mecanismos de defesa do grupo de professores, por um espaço de poder e de controle da ortografia, da leitura oral, da escrita (em tinta ou Braille) e da feitura de provas impressas, constitui-se um dos pólos dessa disputa no ambiente escolar. Por outro lado, a substituição pelo uso do computador para acesso a informação (em que há alguns professores favoráveis), necessita da investida da compreensão do formato digital e seu modo específico para lidar com dados (hipertextualidade, maleabilidade, interatividade), pois são novos tipos de leitores (e autores) que estão em formação pela imersão e interação através de interfaces hipertextuais, chamados de leitores imersivos por Lucia Santaella (2004).

Apesar de existirem focos de mudança, o sujeito compõe e reproduz elementos de uma cultura escolar que reforça e perpetua comportamentos e atitudes (representações compartilhadas a respeito de situações e objetos do mundo), não formando o estudante como pesquisador, seja com ou sem internet. No entanto, a necessidade de lidar com a informação e com a pesquisa em ambiente digital é inerente à reformulação curricular para que novas formas de interagir com o conhecimento e com os assuntos escolares sejam também fontes de interesse dos alunos adolescentes, 
cada vez mais imersos em tais espaços, onde o lazer e a comunicação tem sido um dos principais fatores de atração em detrimento do saber escolar formal.

O enfoque na representação da tecnologia digital e a necessidade de adaptação do currículo precisam ser mais discutidos pelos profissionais de acompanhamento da Educação Especial e do Ensino Regular. Tais adaptações não representam cortes radicais de conteúdo sob desculpa de flexibilidade curricular, mas a reflexão sobre a pertinência dos assuntos abordados nas disciplinas da escola e a sua significação para os alunos na contemporaneidade. Tudo isso deve ser pensado junto com as adaptações de acesso (inclusão digital) que ainda estão longe de serem viabilizadas, a exemplo dos projetos partidários do acesso a um notebook por aluno e por professor ${ }^{6}$.

Para finalizar, não podemos descartar a preocupação de professores com a nãoresponsabilidade de jovens com os próprios estudos, deveres escolares e com a própria apropriação (desejo e opção) da tecnologia adequada (a cada caso, a cada aluno). Isso não perpassa por pura e simples apresentação das tecnologias aos alunos, mas sim o pensar integrado quanto ao currículo e o modo de torná-lo significativo ao estudante, abordando a questão de maneira mais ampla, sejam com ou sem as adaptações proporcionadas pela TA.

\section{Notas}

\footnotetext{
${ }^{1}$ Ata de constituição do CAT pode ser acessada em http://www.mj.gov.br/sedh/ct/corde/dpdh/corde/comite_at.asp

2 Dosvox é um software criado por José Antonio dos Santos Borges e Marcelo Pimentel Pinheiro. O programa é um sistema operacional, com base no MS-DOS que trabalha com sintetização de voz para leitura de e-mails, páginas de internet, escrita de textos, comunicação, jogos e outros tipos de aplicações. É disponibilizado gratuitamente por seus criadores em: < http://intervox.nce.ufrj.br/dosvox/>.

${ }^{3}$ Os grifos feitos pelos autores deste texto serão em negrito itálico. Traduzindo algumas abreviações contidas no email da aluna: $v c=$ você; dvs $=$ deveres.

${ }^{4}$ MSN é sigla para Microsoft Messenger (atualmente chamado de Windows Live Messenger), sendo um meio de comunicação utilizado em larga escala pelos jovens conectados à internet, onde é possível a troca de mensagens de texto e eventualmente conferências através de áudio e vídeo. Já o Orkut é um site para formação de rede de relacionamentos, que entre suas diversas funções permite o debate em comunidades virtuais temáticas e a troca de mensagens com pessoas que fazem parte e estão cadastradas na rede social do usuário.

${ }^{5}$ Este debate foi muito bem sintetizado por André Lemos, na obra Cibercultura (2007, p. 246-255), quando procura analisar um movimento alternativo a estes dois extremos, o tecnorrealismo, e percebe que a solução apresentada, antes de ser consensual e resolver esta dualidade estava mais para um manifesto sutil dos tecnofóbicos, pois os itens de seu manifesto pouco acrescentavam ao debate, piorando a situação ao não permitir que posições a favor ou contra fossem manifestadas e postas em debate, minimizando a necessidade do mesmo.

${ }^{6}$ Projetos como o OLPC (One Laptop Per Child) procuram criar formas de acesso para crianças entrarem na rede internet de maneira barata e eficaz. Para isso propostas de computadores de baixo custo, voltados para crianças pobres e países periféricos têm sido oferecidos a inúmeros países, incluindo o Brasil que tem o seu projeto UCA (Um Computador por Aluno). Ver em <http://laptop.org/en/> Quanto aos professores, em 2008 foram distribuídos cerca de 26 mil notebooks para professores ativos em sala de aula, secretaria e coordenadorias da rede municipal de ensino do Rio de Janeiro, medida esta que procura aproximar os professores da cultura digital e seus possíveis usos em sala de aula.
}

\section{Referências}

BERSCHI, R. Introdução à tecnologia assistiva. Centro Especializado em Desenvolvimento Infantil (CEDI), Porto Alegre, 2008. Disponível em: $<$ http://www.assistiva.com.br/Introducao\%20TA\%20Rita\%20Bersch.pdf> . Acesso em: 14 jun. 2009.

BRETON, P. Le culte de l'Internet: une menace pour Le lien social? Paris, France: 2000. 
CHARTIER, R. Inscrever \& Apagar: cultura escrita e literatura, séculos XI-XVIII. Trad. Luzmara Curcino Ferreira. São Paulo: Editora UNESP, 2007.

DALLABRIDA, A. M.; LUNARDI, G. M. O acesso negado e a reiteração da dependência: a biblioteca e o seu papel no processo formativo de indivíduos cegos. Cadernos Cedes, Campinas, v. 28, n. 75, p. 191-208, 2008.

ECO, Umberto. Apocalípticos e integrados . 6 ed. São Paulo: Perspectiva, 2008.

FREITAS, Maria Teresa de Assunção. Sites construídos por adolescentes: novos espaços de leitura/escrita e subjetivação. Cadernos CEDES, Campinas, v. 25, n. 65, p. 87-101, 2005.

GARBIN, Elisabete Maria. Cultur@s juvenis, identid@des e Internet: questões atuais. Revista Brasileira de Educação, Rio de Janeiro, n. 23, p. 119-135, 2003.

JODELET, D. (org.). Representações sociais. Rio de Janeiro: Ed. UERJ, 2001.

JODELET, D. Loucuras e representações sociais. Petrópolis, RJ: Vozes, 2005.

KEEN, A. O culto do amador. Trad. Maria Luiza X. de A. Borges. Rio de Janeiro: Jorge Zahar Ed., 2009.

LAPLANE, A. L. F.; BATISTA, C. G. Ver, não ver e aprender: a participação de crianças com baixa visão e cegueira na escola. Cadernos Cedes, Campinas, v. 28, n. 75, p. 209-227, 2008.

LEMOS, A. Cibercultura: tecnologia e vida social na cultura contemporânea. 3 ed. Porto Alegre: Sulina, 2007.

LÉVY, P. Cibercultura. Trad. Carlos Irineu da costa. 2 ed. São Paulo: Ed. 34, 1999.

MOSCOVICI, S. A representação social da psicanálise. Trad. Álvaro Cabral. Rio de Janeiro: Zahar Editores, 1978.

Petrópolis: Vozes, 2003.

Representações sociais: investigações em psicologia social.

OLIVEIRA, M. S. B. S. de. Representações sociais e sociedades: a contribuição de Serge Moscovici. Revista brasileira de ciências sociais, São Paulo, v. 19, n. 55, p. 180-186, 2004.

PELOSI, M. B. A comunicação alternativa e ampliada nas escolas do Rio de Janeiro: formação de professores e caracterização dos alunos com necessidades educacionais especiais. Rio de Janeiro: UERJ / ProPEd, 2000. 225p. Dissertação de Mestrado. p. 34-57.

RECUERO, R. Redes sociais na internet. Porto Alegre: Sulina. 2009.

SANTAELLA, Lucia. Navegar no ciberespaço: o perfil cognitivo do leitor imersivo. São Paulo: Palus, 2004.

\section{Anexo I: Notas de campo sobre o contexto dos alunos cegos na escola de $6^{\circ}$ ano}

Não é suficiente narrar em detalhes o que se passa nos diálogos, é necessária uma aproximação das significações e intenções dos grupos de professores em ação, para que se atinja a compreensão do processo de construção das representações sociais, de modo que seja possível compreender a ordem das interações, sendo estas afetivas, cognitivas, materiais e simbólicas.

Para compreensão do processo a que esta aluna cega e outras três moças cegas e um rapaz com baixa visão estão imersos, detalharemos brevemente a forma de acompanhamento dos referidos alunos de $6^{\circ}$ ano. Em relação a recursos tecnológicos, os alunos possuem aulas de informática, com utilização de Dosvox, em sala de informática na própria escola, e a disponibilização de dois MP3s adquiridos pela escola (três destes alunos já possuem MP3). 
A princípio, a utilização do Dosvox na escola, no primeiro ano de implementação da proposta em 2008 (investimento no uso de recursos tecnológicos) ficou restrito aos dias de prova e/ou testes e às aulas de informática.

Arquivos digitalizados dos livros didáticos das matérias que os alunos estejam encontrando maiores dificuldades são disponibilizados em CD ou passados para MP3 com auxílio do professor de informática. Os livros didáticos são transcritos para o Braille pelo Centro de Transcrição à Braille (CTB). Por vezes os livros transcritos são disponibilizados com atraso devido aos capítulos selecionados de forma aleatória e nãosequencial. Percebe-se a tentativa de organização de comunicação da itinerância com CTB para as partes dos livros serem fielmente repassadas de acordo com planejamento, visando o não desperdício de esforços numa seqüência ou quantidade de capítulos equivocada ou até mesmo não utilizada. Ocorre também a falta de recursos, de folhas, devido grande demanda de transcrições.

Os alunos, em geral, pouco solicitam a sala de informática e de leitura para estudo fora do horário de aulas. Os alunos com deficiência visual investem no estudo das matérias por solicitação das professoras de sala de recursos, de itinerância e de informática e sob supervisão destes. Poucos recorreram ao material gravado sobre as disciplinas.

O material a Braille também não era revisto em leituras de estudo realizadas pelos mesmos. Duas alunas destacam-se nas notas, uma delas com maior suporte em casa para tirar dúvidas e lembrá-la de pesquisas (esta é a aluna presente no e-mail) outra, abrigada em instituição religiosa para acolhimento de moças cegas, recorre de forma mais freqüente aos recursos oferecidos (em braille ou em áudio) para estudo, mas também apresenta de forma irregular os deveres de casa.

Os outros três alunos possuem maiores dificuldades nas disciplinas da escola e pouco incentivo e preocupação com a realização de trabalhos escolares: uma delas com bom poder aquisitivo; a outra abrigada na referida instituição religiosa e sem apoios possíveis para feitura dos exercícios a não ser com voluntários ledores; um terceiro aluno, num processo de transição, em que se percebe perda gradativa da visão, é aluno com baixa visão, e não utiliza o braille; recorre ao áudio somente quando cobrado de que estude.

$\mathrm{Na}$ instituição de abrigo das cegas de $2^{\mathrm{a}}$ a $6^{\mathrm{a}}$ feira (de duas delas) há ledores voluntários, mas as mesmas não organizaram as próprias necessidades para estudo e pesquisa e dificilmente recorreram a esses ledores (presentes de forma irregular) em tempo hábil para realização de trabalhos. Existe uma sala de computadores com Dosvox no abrigo, mas a mesma fica trancada, segundo relato das jovens e de voluntários. A situação é justificada devido não haver um acompanhante para utilização diária dos computadores.

A aluna do recorte do e-mail possui bom poder aquisitivo, utiliza diariamente computador (MSN, Orkut, pesquisa de interesses particulares em sites); possui bom desenvolvimento nas matérias escolares, no entanto, ao final do ano letivo, apresentou falta às aulas e algumas notas oscilaram.

A autonomia e a independência dos alunos são cobradas por professores de disciplinas da escola e estes alunos recebem o apoio dos serviços de itinerância, no horário escolar duas a três vezes cada aluno. Foi designado um itinerante específico e único para o acompanhamento da escola. Além do itinerante, os alunos freqüentam duas vezes na semana, no contra-turno, as aulas de sala de recursos.

Os recursos de adaptação, como transcrições de textos diários que são passados além do livro didático, são providenciados pelos professores de sala de recursos e de itinerância (rede de apoio ao estudante da Educação Especial inserido em classe 
comum). Alguns professores de disciplinas, sensibilizados e instruídos pela rede de apoio, a partir da inserção de alunos com deficiência, providenciam materiais adaptados previamente tais como maquetes, experiências no Laboratório de Ciências com materiais para percepção tátil pensados para os alunos cegos e de baixa visão, mas que motivavam aos outros alunos.

São previstos, por professores de disciplinas como de matemática e geografia, entraves nos percursos dos alunos com deficiência visual, antevisão de problemas no futuro das disciplinas, no aumento de materiais para leitura e estudo e na forma de ensinar os conteúdos programados para $6^{\circ}$ ao $9^{\circ}$ ano para alunos com deficiência visual. As adaptações curriculares ficam, no caso dessas matérias, totalmente a cargo dos professores da rede de apoio.

Esses alunos pouco discutem e se posicionam sobre a responsabilidade com os estudos. Quando questionados, sinalizam a independência futura, a ser conquistada, e parecem não notar as possibilidades atuais de apropriação de recursos que garantem maior autonomia. A regularidade é a pouca escuta aos desejos e interesses sinalizados pelos jovens em geral. 